\title{
Cross sectional study of factors associated to self-reported blood-borne infections among drug users
}

Juliana Reyes-Urueña ${ }^{1,2,3,4}$, M. Teresa Brugal ${ }^{4,5}$, Xavier Majo ${ }^{6}$, Antonia Domingo-Salvany ${ }^{2 *}$ and Joan A. Caylà 1,4,5,7

\begin{abstract}
Background: The study's aim was to estimate the self-reported prevalence of Human Immunodeficiency Virus (HIV) and Hepatitis C Virus (HCV), and to describe their associated risk factors in a population of users of illicit drugs recruited in Catalonia- Spain, during 2012.

Methods: Cross-sectional study. People with illicit drugs use were selected in three different types of healthcare centres. The questionnaire was a piloted, structured ad hoc instrument. An analysis was made to identify factors associated to self-reported HCV, HIV and co-infection. Correlates of reported infections were determined using univariate and multivariate Poisson regression (with robust variance).
\end{abstract}

Results: Among 512 participants, $39.65 \%$ self-reported positive serostatus for HCV and $14.84 \%$ for HIV, co-infection was reported by $13.48 \%$. Among the 224 injecting drug users (IDUs), 187 (83.48 \%), 68 (30.36\%) and 66 (29.46\%) reported being positive for HCV, HIV and co-infection, respectively. A higher proportion of HIV-infected cases was observed among women, (18.33 \% vs. 13.78 \% in men). Prevalence of HCV, HIV and co-infection were higher among participants with early onset of drug consumption, long periods of drug injection or who were unemployed. A positive serostatus was self-reported by 21(7.34\%) participants who did not report any injection; among them 16 and eight, reported being positive for HCV and HIV, respectively; three reported co-infection. Only two people declared exchanging sex for money. For those that reported a negative test, the median time since the last HIV test was 11.41 months (inter-quartile range (IQR) 4-12) and for the HCV test was 4.5 months (IQR 2-7).

Conclusions: Among drug users in Catalonia, HIV, HCV and co-infection prevalence are still a big issue especially among IDUs. Women and drug users who have never injected drugs are groups with a significant risk of infection; this might be related to their high-risk behaviours and to being unaware of their serological status.

Keywords: Drug users, Illicit drugs, HIV, Hepatitis, Spain, Risk Factors

\section{Background}

Drug dependence is a complex chronic condition, which is often related to health problems, such as the risk of acquisition of blood-borne pathogens. People who use drugs, especially by injection, have been among the first and largest transmission group for new human immunodeficiency virus (HIV) infections [1], and are still a key transmission group for hepatitis $\mathrm{C}$ virus (HCV) [2]. These infections are among the most costly consequences of

\footnotetext{
* Correspondence: adomingo@imim.es

${ }^{2}$ Drug Use Epidemiology Research Group, IMIM-Hospital del Mar Medical

Research Institute, Dr Aiguader 88, 08003 Barcelona, Spain

Full list of author information is available at the end of the article
}

illicit drug use, having a high impact on individuals and on healthcare systems [3].

Epidemiological studies have described different transmission risk factors for $\mathrm{HIV} / \mathrm{HCV}$ among drug users. Injecting drugs is the leading source of infection, and among non-injecting users it is sexual contact [4]. Among injecting drug users (IDUs), HIV has a global prevalence of approximately $11.5 \%$ and HCV of $51.0 \%$ [5], mainly as a result of sharing contaminated syringes and other injecting equipment $[6,7]$. Unprotected sex is one of the most important risk factors for HIV in drug users who have never injected drugs [4], with an increased risk of infection by $\mathrm{HCV}$ among women and 
men who have sex with men who are co-infected with HIV or other sexually transmitted diseases [8]. Other sex-related factors associated with the increased risk of blood-borne infections (BBI) include a history of a sexually transmitted disease [9], sex with an IDU partner [10], exchanging sex for money or drugs [11] and number of sex partners [12].

Data from surveillance systems and cohort studies suggest that prevalence of both infections are high among IDUs. HCV is five times more prevalent than HIV, and has remained unchanged even in communities where the rate of HIV infections has fallen [13]. In Spain, HIV prevalence in IDUs seems to be decreasing, although it is still high compared with other European countries [14]. In contrast prevalence of HCV among IDUs has remained stable or increased slightly in recent years [3]. In Catalonia, a Spanish Autonomous Community, one study showed that during 2006, prevalence of HIV and HCV among IDUs were 58.1 and $80.1 \%$, respectively [15], with $50.3 \%$ of co-infection.

In view of the above factors, drug users constitute a vulnerable group needing continual surveillance, especially because they constitute a key group in which to focus preventive interventions that can reduce transmission of BBI. The objective of this study was to estimate the prevalence of self-reported HIV and HCV, and to describe factors associated with them, in a large sample of consumers of illicit drugs recruited in Catalonia- Spain, during 2012.

\section{Methods}

\section{Study design and population}

Cross-sectional study in Catalonia, Spain, where participants were selected from three different drug healthcare settings: 1) Substance abuse outpatient treatment centres (OTC), 2) Harm Reduction facilities (HRF) and 3) Therapeutic communities (TC). Sampling was planned to achieve good geographical coverage. Each centre was assigned a number of participants to be recruited, according to their activity, over-sampling the smallest, especially in HRF. In the OTC this was done only for those having more than 45 annual patients; and in each OTC a convenience sample was selected taking into account whether first treatment and time in treatment. In the HRF, individuals were paid $10 €$ for their participation. All participants who agreed to participate signed a consent form. The study was approved by the IMIM-Hospital del Mar Medical Research Institute ethical committee. Field-work was conducted from April to June 2012. Serologic testing was not used; therefore infection prevalence calculated in the analysis are based on self-reported data.

\section{Questionnaire}

The questionnaire was a piloted, structured ad hoc instrument. The questionnaire was anonymised and included questions related to socio-demographic characteristics (age, sex, country of birth, marital status, educational level and employment status), patterns of drug consumption (drugs, periods of consumption and whether or not injecting), prison history (ever been convicted of a crime or imprisoned) and self-reported HIV and HCV serological status. Information on HCV and HIV serological status was retrieved from questions asking whether they had ever had a blood test for HIV/HCV (one at a time) and, if so, when was the last test and whether a positive result was ever given. Injecting drug users were defined as individuals reporting any drug injection at least once in their lifetime.

\section{Statistical analysis}

An analysis was made to identify factors associated to self-reported HIV, HCV and co-infection. Self-reported co-infected individuals were included in the total number of infected individuals for self-reported HIV and self-reported HCV when analysed separately. Only subjects reporting positive serology were considered as such and were compared to subjects either negative or with unknown serostatus. The descriptive analysis included socio-demographic characteristics, pattern of drug consumption and prison history. Comparisons were made to provide insight into which factors were linked to selfreported blood borne infections. Correlates were determined using a Poisson regression with robust variance. Poisson regression was used instead of logistic regression because of the high prevalence of infections and because it allows for direct estimation of self-reported prevalence ratios (PRs), along with $95 \%$ confidence intervals [CIs]. The chi-square test for categorical variables was used to compare self-reported BBI differences among IDUs and drug users who have never injected drugs.

Multivariate models were constructed to identify independent correlates of self-reported infection for each HIV/HCV self-reported infection and co-infection. The covariates included into the model were: age, sex, country of birth, current marital status, educational level, current employment status, injecting drug user, and prison history. Models included covariates determined to be statistically important on the basis of associations with self-reported infection in the univariate analysis $(p<0.20)$ and only the statistically significant ones were retained. The level of significance was set at $p$ value $<0.05$. Data analysis was performed using PASW Statistics for Windows, version 18.0.

\section{Results}

Forty seven centres were included for the sampling of participants (22 OTC, $13 \mathrm{HRF}$ and $12 \mathrm{TC}$ ). A total of 558 individuals with illegal drugs use were approached for the study: 362 in OTC, 99 in HRF, and 97 in TC. Forty-two people refused to participate, due to: lack of 
time (45\%), were not interested (19\%) and unknown reasons $(31 \%)$. In addition, four questionnaires were excluded because they were incomplete (two of them didn't report any information related to their serostatus).

A total of 512 individuals were studied, with a median age of 39 years, $76.56 \%$ were male, $57.81 \%$ had used heroin and $93.42 \%$ had used cocaine. Overall, 210 subjects $(41.02 \%)$ self-reported being positive either for $\mathrm{HIV}$ and/or HCV; the prevalence of HCV was $39.65 \%$, for HIV it was $14.84 \%$, co-infection being reported by $13.48 \%$ subjects. For all proportions, the denominator includes 83 participants who didn't know their serostatus (either never been tested or results unknown). Tables 1,2 and 3 show the comparisons of sociodemographic and drug consumption characteristics of self-reported HIV, HCV and co-infection.

The three self-reported serological status groups shared similar associations. The median age of selfreported infected subjects was 41 years for HIV and 42 years for $\mathrm{HCV}$ and HIV/HCV co-infection. The prevalence of self-reported HIV was $18.33 \%$ among women and $13.78 \%$ among men $(p=<0.001)$. Among self-reported HCV cases, a higher proportion was found among men (40.56\%), compared to women (36.67\%), whereas for self-reported co-infection cases, the proportion was slightly higher for women (14.17\% vs $13.27 \%$ for men).

The prevalence of HIV, HCV and co-infection increased with early onset of drugs consumption. In the univariate analysis for the three self-reported serostatus scenarios, long periods of drug injection were found to be associated to self-reported infection (participants with longer periods of injection being more likely to selfreport infection). Self-reported infections among participants who started drug consumption more recently (2001-2012), [51(9.96 \%)] were much less common, with only a few cases of HIV [3(3.95\%)], HCV [2(0.99\%)] and co-infection [1(1.45\%)]. In the multivariate analysis heroin use was only found to be significant for selfreported $\mathrm{HCV}$ infection. Nevertheless, $10 \mathrm{HCV}$ positive participants did not report heroin consumption, just cocaine.

Table 4 describes self-reported serostatus according to informed parenteral use ever. From the 510 subjects with known history of parenteral use, 224 (43.92 \%) individuals reported having injected drugs at least once, and of these, $187(83.48 \%)$ individuals self-reported to be positive for HCV and 68 (30.36 \%) for HIV, 66 (29.46 \%) individuals were co-infected. Among the drug users who reported never having injected drugs $(N=286,56.08 \%)$, 164 (57.34 \%) participants self-reported being negative for both infections the last time they were tested, and 101 (35.44 \%) were unaware of their serostatus either for one infection or both. Twenty-one (7.34\%) participants self-reported a positive serostatus for HIV and/or HCV but did not report any parenteral use. Among these 21 individuals, 16 self-reported being positive for $\mathrm{HCV}$, and eight for HIV, three reported co-infection. Only two people declared exchanging sex for money. For those that reported a negative test, the median time since the last HIV test was 11.41 months (inter-quartile range (IQR) 412) and for the HCV test was 4.5 months (IQR 2-7).

\section{Discussion}

In this study of drug users in Catalonia, a high prevalence of self-reported HCV (39.65\%) was observed, with moderate prevalence of self-reported HIV (14.84 \%) and co-infection (13.48 \%). As expected these self-reported infections were strongly associated with parenteral drug use and length of drug consumption. However, women were more likely to report being HIV infected or coinfected, and there was a high proportion of drug users who have never injected drugs who were unaware of their serological status. A small proportion (7.34 \%) of drug users reporting never having injected drugs reported being infected.

These results are in line with those of other studies which suggest that despite the introduction of preventive interventions (screening, counselling, needle and syringe exchange programs, methadone programs and other treatments for substance abuse), transmission persists and prevalence of blood borne infections, particularly $\mathrm{HCV}$, continues to be notable in high-risk groups [16], such as drug users especially IDUs. Currently in Spain, the route of HIV transmission for $28 \%$ of all Acquired Immunodeficiency syndrome (AIDS) cases is IDU [17], and in Europe and the USA, IDU's account for more than $60 \%$ of new HCV infections $[4,17]$.

Our results showed that women who use drugs had a higher likelihood to self-report HIV infection, than men who use drugs, but unfortunately, sexual transmission factors were not collected. Some studies have reported that women who use drugs more often engage in risky sexual behaviours, being more likely than men to have unprotected sex, to have multiple sex partners, to engage in sex for money or drugs, to use a greater variety of drugs than men and to be at a higher risk of suffering violence and marginalization [18-21]. Despite a decrease in the HIV/AIDS epidemic among IDUs, significant gender differences persist. Women in drug care facilities constitute a minority, and their gender specific needs may often be overlooked. Therefore, in the implementation of HIV prevention strategies, it is crucial to consider a gender perspective when focusing needs of drug consumers.

Comparing our study with others conducted in Catalonia $[15,16]$, prevalence of BBI are similar. However, we have found a large number of individuals with unknown 
Table 1 Socio-demographic and drug consumption variables associated to self-reported HIV, from drug users in Catalonia, 2012

\begin{tabular}{|c|c|c|c|c|c|}
\hline & Total & HIV positive & HIV negative & Bivariate analysis $^{a}$ & Multivariate analysis ${ }^{\mathrm{b}}$ \\
\hline & $n=512$ & $n=76(\%)$ & $n=436(\%)$ & PR (95\% Cl) & PR (95\% Cl) \\
\hline Age, median (IQR) & 39 [35-44] & $41[37-45]$ & $36[32-43]$ & $1(1.02-1.06)$ & $1.007(0.98-1.04)$ \\
\hline \multicolumn{6}{|l|}{ Sex } \\
\hline Men & $392(76.56)$ & $54(13.78)$ & $338(86.22)$ & 1 & 1 \\
\hline Women & $120(23.44)$ & $22(18.33)$ & $98(81.67)$ & $1.32(0.84-2.08)$ & $1.96(1.27-3.04)$ \\
\hline \multicolumn{6}{|l|}{ Country of birth } \\
\hline Spain & $462(90.23)$ & $67(14.50)$ & $395(85.50)$ & 1 & \\
\hline Other countries & $48(9.38)$ & $8(16.67)$ & $40(83.33)$ & $1.15(0.59-2.26)$ & \\
\hline Unknown & $2(0.39)$ & $1(50)$ & $1(50)$ & - & \\
\hline \multicolumn{6}{|l|}{ Current marital status } \\
\hline Single & $275(53.71)$ & $46(16.73)$ & $229(83.27)$ & 1 & \\
\hline Married & $120(23.44)$ & $18(15)$ & $102(85)$ & $0.89(0.54-1.47)$ & \\
\hline Divorced & 89 (17.38) & $12(13.48)$ & 77 (86.52) & $0.80(0.44-1.44)$ & \\
\hline Unknown & $28(5.47)$ & - & $28(100)$ & - & \\
\hline \multicolumn{6}{|l|}{ Educational level } \\
\hline Primary education or less & $155(30.27)$ & $28(18.06)$ & $127(81.94)$ & 1 & \\
\hline Secondary education & $203(39.65)$ & $27(13.30)$ & $176(86.70)$ & $0.73(0.45-1.19)$ & \\
\hline Undergraduate education & $154(30.08)$ & $21(13.64)$ & $133(86.36)$ & $0.75(0.45-1.26)$ & \\
\hline \multicolumn{6}{|l|}{ Current employment status } \\
\hline Current regular job & $111(21.68)$ & $2(1.80)$ & $109(98.20)$ & 1 & 1 \\
\hline Unemployment & $277(54.1)$ & $38(13.72)$ & $239(86.28)$ & $7.75(1.9-31.59)$ & $5.00(1.26-19.91)$ \\
\hline Disabled or retired & 99 (19.34) & $35(35.35)$ & $64(64.65)$ & $19.98(4.93-80.94)$ & $8.92(2.24-35.60)$ \\
\hline Others, including never has worked and worked at home & $25(4.88)$ & $1(4)$ & $24(96)$ & $2.26(0.21-23.96)$ & $1.71(0.22-12.99)$ \\
\hline \multicolumn{6}{|l|}{ Number of years by injecting drug consumption } \\
\hline Non-injecting users & $286(55.86)$ & $8(2.80)$ & $278(97.20)$ & 1 & 1 \\
\hline Injection for $<6$ years & $58(11.33)$ & $10(17.24)$ & $48(82.76)$ & $6.19(2.55-15.00)$ & $4.88(2.08-11.46)$ \\
\hline Injection for 6 to 12 years & $27(5.27)$ & $7(25.93)$ & $20(74.07)$ & $9.30(3.65-23.68)$ & $7.73(3.08-19.37)$ \\
\hline Injection 13 to 22 years & $68(13.28)$ & $29(42.65)$ & $39(57.35)$ & $15.30(7.32-31.96)$ & $12.10(5.76-25.41)$ \\
\hline Injection for $>22$ years & $52(10.16)$ & $18(34.62)$ & $34(65.38)$ & $12.42(5.70-27.05)$ & $7.73(3.08-19.37)$ \\
\hline Injection for unknown time & $21(4.1)$ & $4(19.05)$ & $17(80.95)$ & $6.52(2.13-19.98)$ & $4.30(1.19-15.52)$ \\
\hline Years after starting drug use, median (IQR) & $8.5[2.4-13.77]$ & $17[4.80-22.75]$ & $0[0-4.8]$ & $1.05(1.03-1.08)$ & \\
\hline \multicolumn{6}{|l|}{ Period of onset of the $1^{\text {st }}$ drug use } \\
\hline $2001-2012$ & $51(9.96)$ & $3(5.88)$ & $48(94.12)$ & 1 & \\
\hline $1991-2000$ & 199 (38.87) & $15(7.54)$ & $184(92.46)$ & $1.28(0.38-4.24)$ & \\
\hline $1981-1990$ & $195(38.09)$ & $44(22.56)$ & $151(77.44)$ & $3.82(1.24-11.79)$ & \\
\hline 1953-1980 & $64(12.5)$ & $13(20.31)$ & $51(79.69)$ & $3.45(1.04-11.47)$ & \\
\hline Unknown period & $3(0.59)$ & $1(33.33)$ & $2(66.67)$ & $5.67(0.81-39.46)$ & \\
\hline \multicolumn{6}{|l|}{ Heroin use } \\
\hline No & $216(42.19)$ & $5(2.31)$ & 211 (97.69) & 1 & \\
\hline Yes & $296(57.81)$ & 71 (23.99) & $225(76.01)$ & $10.46(4.30-25.46)$ & \\
\hline \multicolumn{6}{|l|}{ Prison History } \\
\hline No & 393 (76.56) & $45(11.45)$ & 348 (88.55) & 1 & \\
\hline Yes & $119(23.24)$ & $31(26.05)$ & $88(73.95)$ & $3.52(1.95-6.37)$ & \\
\hline
\end{tabular}

HIV human immunodeficiency virus, $I Q R$ interquartile range, $P R$ prevalence ratio, $C l$ confidence intervals

a Univariate Poisson regression models with robust variance

${ }^{b}$ Multivariate Poisson regression model included covariates determined to be statistically important on the basis of associations with infection in the univariate analysis $(p<0.2)$ 
Table 2 Socio-demographic and drug consumption variables associated to self-reported HCV, from drug users in Catalonia, 2012

\begin{tabular}{|c|c|c|c|c|}
\hline & HCV positive & HCV negative & Bivariate analysis $^{\mathrm{a}}$ & Multivariate analysis ${ }^{b}$ \\
\hline & $n=203(\%)$ & $n=309(\%)$ & PR $(95 \%$ Cl) & PR $(95 \%$ Cl) \\
\hline Age, median (IQR) & $42[37-46]$ & $35[31-41]$ & $1.05(1.04-1.06)$ & $1.02(1.01-1.03)$ \\
\hline \multicolumn{5}{|l|}{ Sex } \\
\hline Men & $159(40.56)$ & $233(59.44)$ & 1 & 1 \\
\hline Women & $44(36.67)$ & $76(63.33)$ & $0.9(0.69-1.17)$ & $1.15(0.99-1.36)$ \\
\hline \multicolumn{5}{|l|}{ Country of birth } \\
\hline Spain & 179 (38.74) & $283(61.26)$ & 1 & \\
\hline Other countries & $22(45.83)$ & $26(54.17)$ & $1.19(0.86-1.65)$ & \\
\hline Unknown & $2(100)$ & - & & \\
\hline \multicolumn{5}{|l|}{ Current marital status } \\
\hline Single & $112(40.73)$ & $163(59.27)$ & 1 & \\
\hline Married & $51(42.50)$ & $69(57.50)$ & $1.04(0.8-1.33)$ & \\
\hline Divorced & $33(37.08)$ & $56(62.92)$ & $0.9(0.66-1.22)$ & \\
\hline Unknown & $7(25)$ & $21(75)$ & - & \\
\hline \multicolumn{5}{|l|}{ Educational level } \\
\hline Primary education or less & $71(45.81)$ & $84(54.19)$ & 1 & \\
\hline Secondary education & $80(39.41)$ & $123(60.59)$ & $0.86(0.67-1.09)$ & \\
\hline Undergraduate education & $52(33.77)$ & $102(66.23)$ & $0.73(0.55-0.97)$ & \\
\hline \multicolumn{5}{|l|}{ Current employment status } \\
\hline Current regular job & $17(15.32)$ & $94(84.68)$ & 1 & 1 \\
\hline Unemployment & 109 (39.35) & $168(60.65)$ & $2.62(1.65-4.15)$ & $1.52(1.15-2.56)$ \\
\hline Disabled or retired & $69(69.70)$ & $30(30.30)$ & $4.63(2.93-7.32)$ & $1.77(1.30-2.40)$ \\
\hline Others, including never has worked and worked at home & $8(32.0)$ & $17(68.0)$ & $2.13(1.04-4.37)$ & $1.51(1.12-2.06)$ \\
\hline \multicolumn{5}{|l|}{ Number of years by injecting drug consumption } \\
\hline Non-injecting users & $16(5.59)$ & $270(94.41)$ & 1 & 1 \\
\hline Injection for $<6$ years & $35(60.34)$ & $23(39.66)$ & $10.82(6.44-18.2)$ & $5.88(3.27-13.74)$ \\
\hline Injection for 6 to 12 years & $23(85.19)$ & $4(14.81)$ & $15.28(9.25-25.23)$ & $7.88(4.46-13.94)$ \\
\hline Injection 13 to 22 years & $63(92.65)$ & $5(7.35)$ & $16.62(10.28-26.88)$ & $7.77(4.40-13.74)$ \\
\hline Injection for $>22$ years & $52(100)$ & - & $17.94(11.14-28.88)$ & $7.98(4.49-14.19)$ \\
\hline Injection for unknown time & $14(66.67)$ & $7(33.33)$ & $11.42(6.45-20.21)$ & $5.89(3.14-11.03)$ \\
\hline Years after starting drug use, median (IQR) & $26[20-30]$ & 17 [12-23] & $1.07(1.05-1.08)$ & $5.80(3.09-10.91)$ \\
\hline \multicolumn{5}{|l|}{ Period of onset of the $1^{\text {st }}$ drug use } \\
\hline $2001-2012$ & $2(3.92)$ & $49(96.08)$ & 1 & \\
\hline $1991-2000$ & $46(23.12)$ & $153(76.88)$ & $5.87(1.47-23.36)$ & \\
\hline 1981-1990 & $111(56.92)$ & $84(43.08)$ & $14.44(3.69-56.49)$ & \\
\hline 1953-1980 & $43(67.19)$ & $21(32.81)$ & $17.13(4.36-67.37)$ & \\
\hline Unknown period & $1(33.33)$ & $2(66.67)$ & $8.5(1.04-69.35)$ & \\
\hline \multicolumn{5}{|l|}{ Heroin use } \\
\hline No & $10(4.63)$ & $206(95.37)$ & 1 & 1 \\
\hline Yes & $193(65.20)$ & $103(34.80)$ & $14.21(7.72-26.19)$ & $2.86(1.42-5.75)$ \\
\hline \multicolumn{5}{|l|}{ Prison history } \\
\hline No & $124(31.55)$ & $269(68.45)$ & 1 & \\
\hline Yes & $79(66.39)$ & $40(33.61)$ & $3.35(2.41-4.65)$ & \\
\hline
\end{tabular}

$H C V$ Hepatitis $C$ virus, IQR interquartile range, $P R$ prevalence ratio, $C l$ confidence intervals anivariate Poisson regression models with robust variance

${ }^{\mathrm{b}}$ Multivariate Poisson regression model included covariates determined to be statistically important on the basis of associations with reported infection in the univariate analysis $(p<0.2)$ 
Table 3 Socio-demographic and drug consumption variables associated to self-reported co-infection (HIV/HCV). Drug users in Catalonia, 2012

\begin{tabular}{|c|c|c|c|c|}
\hline & $\begin{array}{l}\text { Positive Co-infection } \\
\text { HIV/HCV }\end{array}$ & $\begin{array}{l}\text { Negative Co-infection } \\
\text { HIV/HCV }\end{array}$ & Bivariate analysis $^{\mathrm{a}}$ & Multivariate analysis $^{b}$ \\
\hline & $n=69(\%)$ & $n=443(\%)$ & PR $(95 \%$ Cl) & PR $(95 \%$ Cl) \\
\hline Age, median (IQR) & $42[37-45]$ & 37 [32-43] & $1.05(1.03-1.07)$ & $1.01(0.99-1.04)$ \\
\hline \multicolumn{5}{|l|}{ Sex } \\
\hline Men & $52(13.27)$ & $340(86.73)$ & 1 & 1 \\
\hline Women & $17(14.17)$ & $103(85.83)$ & $1.06(0.64-1.77)$ & $1.62(1.01-2.60)$ \\
\hline \multicolumn{5}{|l|}{ Country of birth } \\
\hline Spain & $61(13.20)$ & $401(86.80)$ & 1 & \\
\hline Other countries & $7(14.58)$ & $41(85.42)$ & $1.11(0.54-2.29)$ & \\
\hline Unknown & $1(50)$ & $1(50)$ & & \\
\hline \multicolumn{5}{|l|}{ Current marital status } \\
\hline Single & $42(15.27)$ & $233(84.73)$ & 1 & \\
\hline Married & $18(15)$ & $102(85)$ & $0.97(0.59-1.62)$ & \\
\hline Divorced & $9(10.11)$ & $80(89.89)$ & $0.66(0.33-1.29)$ & \\
\hline Unknown & - & $28(100)$ & - & \\
\hline \multicolumn{5}{|l|}{ Educational level } \\
\hline Primary education or less & $24(15.48)$ & $131(84.52)$ & 1 & \\
\hline Secondary education & $25(12.32)$ & $178(87.68)$ & $0.79(0.47-1.33)$ & \\
\hline Undergraduate education & $20(12.99)$ & $134(87.01)$ & $0.52(0.83-0.48)$ & \\
\hline \multicolumn{5}{|l|}{ Current employment status } \\
\hline Current regular job & $1(0.90)$ & $110(99.10)$ & 1 & 1 \\
\hline Unemployment & $34(12.27)$ & $243(87.73)$ & $13.87(1.92-100.11)$ & $8.16(1.17-56.92)$ \\
\hline Disabled or retired & $33(33.33)$ & $66(66.67)$ & $37.67(5.25-270.38)$ & $14.10(1.98-100.48)$ \\
\hline $\begin{array}{l}\text { Others, including never has worked and } \\
\text { worked at home }\end{array}$ & 1 (4) & $24(96)$ & $4.52(0.29-69.84)$ & $3.24(0.28-37.89)$ \\
\hline \multicolumn{5}{|c|}{ Number of years by injecting drug consumption } \\
\hline Non-injecting users & $3(1.05)$ & $283(98.95)$ & 1 & 1 \\
\hline Injection for $<6$ years & $10(17.24)$ & $48(82.76)$ & $16.49(4.68-58.09)$ & $13.04(3.80-44.78)$ \\
\hline Injection for 6 to 12 years & $7(25.93)$ & $20(74.07)$ & $24.80(6.80-90.43)$ & $19.50(5.39-70.55)$ \\
\hline Injection 13 to 22 years & $28(41.18)$ & $40(58.82)$ & $39.39(12.34-125.78)$ & $29.07(9.06-93.24)$ \\
\hline Injection for $>22$ years & $18(34.62)$ & $34(65.38)$ & $33.12(10.12-108.42)$ & $22.77(6.90-75.19)$ \\
\hline Injection for unknown time & $3(14.29)$ & $18(85.71)$ & $13.05(2.80-60.88)$ & $6.98(1.25-39.06)$ \\
\hline Years after starting drug use, median (IQR) & $26[21-30]$ & $20[14-27]$ & $1.06(1.04-1.09)$ & \\
\hline \multicolumn{5}{|l|}{ Period of onset of the $1^{\text {st }}$ drug use } \\
\hline $2001-2012$ & $1(1.96)$ & $50(98.04)$ & 1 & \\
\hline $1991-2000$ & $12(6.03)$ & $187(93.97)$ & $3.06(0.41-22.99)$ & \\
\hline $1981-1990$ & $42(21.54)$ & $153(78.46)$ & $10.93(1.54-77.51)$ & \\
\hline 1953-1980 & $13(20.31)$ & $51(79.69)$ & $10.36(1.40-76.58)$ & \\
\hline Unknown period & $1(33.33)$ & $2(66.67)$ & $17.00(1.37-210.31)$ & \\
\hline \multicolumn{5}{|l|}{ Heroin use } \\
\hline No & $2(0.93)$ & 214 (99.07) & 1 & \\
\hline Yes & $67(22.64)$ & $229(77.36)$ & $24.67(6.11-99.60)$ & \\
\hline \multicolumn{5}{|l|}{ Prison history } \\
\hline No & $39(9.92)$ & 354 (90.08) & 1 & \\
\hline Yes & $30(25.21)$ & 89 (74.79) & $3.90(2.04-7.45)$ & \\
\hline
\end{tabular}

$H C V$ Hepatitis $C$ virus, HIV human immunodeficiency virus, $I Q R$ interquartile range, $P R$ prevalence ratio, $C I$ confidence intervals aUnivariate Poisson regression models with robust variance

${ }^{b}$ Multivariate Poisson regression model included covariates determined to be statistically important on the basis of associations with co-infection in the univariate analysis $(p<0.2)$ 
Table 4 Self-reported HCV and/or HIV positive, negative and unknown serostatus by parenteral use ${ }^{a}$. Catalonia, 2012

\begin{tabular}{|c|c|c|c|c|}
\hline & Injecting drug users & Non-injecting users & Total & $p$-value \\
\hline & $n=224(\%)^{c}$ & $n=286(\%)^{d}$ & $n=510^{f}(\%)^{e}$ & \\
\hline $\mathrm{HCV}$ & $187(83.48)$ & $16(5.59)$ & $203(39.80)$ & $<0.001$ \\
\hline HIV & $68(30.36)$ & $8(2.80)$ & $76(14.90)$ & $<0.001$ \\
\hline $\mathrm{HCV}+\mathrm{HIV}$ & $66(29.46)$ & $3(1.05)$ & $69(13.53)$ & $<0.001$ \\
\hline Negative self-report of HCV and HIV & $26(11.61)$ & $164(57.34)$ & $190(37.25)$ & \\
\hline Unknown serostatus for HCV & $3(1.34)$ & $24(8.39)$ & $27(5.29)$ & \\
\hline Unknown serostatus for HIV & $4(1.79)$ & $23(8.04)$ & $27(5.29)$ & \\
\hline Unknown serostatus for HCV and HIV & $2(0.89)$ & 54 (18.88) & $56(10.98)$ & \\
\hline
\end{tabular}

HIV human immunodeficiency virus, HCV Hepatitis C virus

${ }^{a}$ First three rows in the table are not mutually exclusive

${ }^{\mathrm{b}} \mathrm{Chi}$ square test

cPercentages are the proportion among injecting drug users (IDUs). They do not add up to 100 because co-infected individual count in several categories

${ }^{d}$ Percentages are the proportion among drug users who have never injected drugs. They do not add up to 100 because co-infected individual count in several categories

ePercentages are the proportion among the total. They do not add up to 100 because co-infected individual count in several categories

${ }^{\mathrm{f}}$ Two cases were not included into the analysis due to missing information related with history of drug injection. One reported negative serostatus and the other one unknown HIV serostatus

serostatus, especially among drug users who have never injected drugs. In the literature, researchers and policymakers have a tendency to focus BBI intervention on IDUs, ignoring the risk of individuals who use drugs by other routes. Although one of the most important predictors for BBI seroconversion is starting injection [22], many risks have been described among drug users who have never injected drugs, such as high levels of mixing or "bridging" with the IDU population [23], and high levels of unprotected sex [24, 25]. Since 2008 the Catalan Surveillance system for HIV and HCV (in persons who inject drugs) recruits from harm reduction centres IDUs having injected drugs in the previous 6 months. There is no formal behavioural surveillance system for drug users who don't inject. Therefore behavioural surveillance should regularly monitor rates of transmission from IDUs to drug users who have never injected drugs, by including non-injecting users in the surveillance system, in order to enable the implementation of timely interventions. In fact, the literature describes that behavioural surveillance systems should be integrated in prevention programs that reduce the likelihood of switching from non-injecting routes to drug injection [26-28]. Also, it is important to offer periodic/follow-up and testing access to persons with ongoing risk factors for exposure to BBIs, and to offer information to infected persons; particularly to those who use drugs by injection, about precautions to avoid exposing others to infected blood.

\section{Strengths and limitations}

One of the strengths of this study is the large sample size and the fact that data were collected from different types of centres and in towns of different sizes in Catalonia, thus contributing to the study's external validity. Results might reflect changes in the epidemiology of HIV and HCV in drug users seeking treatment for substance abuse or safe injecting places in urban areas. However, as the sample was recruited only from healthcare centres, we cannot extrapolate our results to drug users who do not access these centres. Nevertheless, our results do not differ greatly from those of studies with street-recruited participants (i.e. not selected from therapeutic centres) [13].

Among other limitations of this paper we must mention, first, that it is not possible to make causal inferences due to the study design. However in order to achieve a more precise assessment of the association in this type of study design, we used a Poisson regression model. Second, the rate of BBI positivity may be an underestimate, first because there was a high proportion of individuals who reported not having had a serological test in the last six months and second because it was based on self-reported serostatus, and thus subject to recall and social desirability biases. In order to reduce the latter, we stressed to participants that their anonymity was guaranteed. Besides, different studies have shown that the main results in cross sectional studies are not seriously affected by these forms of bias, and that the results obtained may be valid despite being self-reported [29]. Third, it is important to mention that it was not possible to confirm serological status among positive cases, and that among negative cases there is still quite a high chance that they could be infected without knowing it. Even so, prevalence of infection obtained in this study does not differ greatly compared to other studies among IDUs [15] .

\section{Conclusions}

Among drug users in Catalonia, prevalence of HIV, HCV and co-infection is still a big issue, especially among IDUs. However, women and drug users who have never injected drugs are groups with a significant risk of infection; this 
might be related to their engaging in high-risk behaviours and to ignorance of their serological status. Therefore, it is crucial to strengthen behavioural surveillance systems in order to ascertain the serostatus of target populations such as drug users who have never injected drugs, offering rapid testing, ensuring access to health care and planning preventive strategies adapted to the profile of specific subpopulations with a gender-sensitive approach.

\section{Competing interest}

The authors declare that they have no competing interest.

\section{Authors' contributions}

ADS, MTB and XM obtained funding and supervised the study. ADS and MTB were responsible for the study concept, design and study implementation. JRU, ADS, MTB and JAC interpreted data. JRU analysed the data and wrote the first draft of the manuscript that was subsequently improved by the rest of the authors. All authors read and approved the final manuscript.

\section{Acknowledgements}

Funding for this study was provided by Spanish Government Grant: Instituto de Salud Carlos III -FIS PI11/01358. Further financial support was provided by the Agència de Gestió d'Ajuts Universitaris i de Recerca (AGAUR 2009 SGR 718) and FIS-Redes de investigación cooperativa RD12/0028/0018. Our thanks to the participants, the collaborating centres and their professionals. We also are grateful to Dave Macfarlane for English revision.

\section{Author details}

'Department of Paediatrics, Gynaecology and Preventive Medicine, Universidad Autónoma de Barcelona, Barcelona, Spain. ${ }^{2}$ Drug Use Epidemiology Research Group, IMIM-Hospital del Mar Medical Research Institute, Dr Aiguader 88, 08003 Barcelona, Spain. ${ }^{3}$ Teaching Unit of Preventive Medicine and Public Health, PSMAR-UPF-ASPB, Barcelona, Spain. ${ }^{4}$ Public Health Agency of Barcelona, Barcelona, Spain. ${ }^{5}$ Institute of Biomedical Research Sant Pau (IIB Sant Pau), Barcelona, Spain. ${ }^{6}$ Department of Health Government of Catalonia, Barcelona, Spain. ${ }^{7}$ CIBER in Epidemiology and Public Health (CIBERESP), Spain.

Received: 19 February 2015 Accepted: 22 October 2015

Published online: 13 November 2015

\section{References}

1. Mathers BM, Degenhardt L, Bucello C, Lemon J, Wiessing L, Hickman M. Mortality among people who inject drugs: a systematic review and meta-analysis. Bull World Health Organ. 2013;91:102-23.

2. Lavanchy D. Evolving epidemiology of hepatitis C virus. Clin Microbiol Infect. 2011;17:107-15.

3. Wiessing L, Likatavicius G, Hedrich D, Guarita B, van de Laar M, Vicente J. Trends in HIV and hepatitis $C$ virus infections among injecting drug users in Europe, 2005 to 2010. Euro Surveill. 2011;16:20031.

4. Strathdee SA, Stockman JK. Epidemiology of HIV among injecting and noninjecting drug users: current trends and implications for interventions. Curr HIV/AIDS Rep. 2010;7:99-106

5. United Nations Office on Drugs and Crime (UNODC). World Drug Report 2013. 2013. http://www.unodc.org/unodc/secured/wdr/wdr2013/ World_Drug_Report_2013.pdf. Accessed 12 November 2015.

6. Chitwood DD, Griffin DK, Comerford M, Page JB, Trapido EJ, Lai S, et al. Risk factors for HIV-1 seroconversion among injection drug users: a case-control study. Am J Public Health. 1995:85:1538-42.

7. Jose B, Friedman SR, Neaigus A, Curtis R, Grund J-PC, Goldstein MF, et al. Syringe-mediated drug-sharing (backloading): a new risk factor for HIV among injecting drug users. AIDS. 1993;7:1653-60.

8. Rania A, Holmberg SD. Is sexual contact a major mode of hepatitis $C$ virus transmission? Hepatology. 2010;52:1497-505.

9. Alcabes $P$, Friedland $G$. Injection drug use and human immunodeficiency virus infection. Clin Infect Dis. 1995;20:1467-79.

10. Campbell CA. Women and AIDS. Soc Sci Med. 1990;30:407-15.
11. Astemborski J, Vlahov D, Warren D, Solomon L, Nelson KE. The trading of sex for drugs or money and HIV seropositivity among female intravenous drug users. Am J Public Health. 1994;84:382-7.

12. Booth RE, Watters JK, Chitwood DD. HIV risk-related sex behaviors among injection drug users, crack smokers, and injection drug users who smoke crack. Am J Public Health. 1993;83:1144-8.

13. March JC, Oviedo-Joekes E, Romero M. Factors associated with reported hepatitis $\mathrm{C}$ and HIV among injecting drug users in ten European cities. Enferm Infecc Microbiol Clin. 2007;25:91-7.

14. Ministerio de Sanidad, Servicios Sociales e Igualdad. Plan Multisectorial frente a la infección por VIH y el sida. España 2008-2012. 2012. https:// www.msssi.gob.es/ciudadanos/enflesiones/enfTransmisibles/sida/docs/ PMS200812.pdf. Accessed 12 November 2015.

15. Huntington S, Folch C, Gonzalez V, Merono M, Ncube F, Casabona J, Prevalence of human immunodeficiency virus and hepatitis $C$ virus, and associated factors among injecting drug users in Catalonia. Enferm Infecc Microbiol Clin. 2010;28:236-8.

16. Muga R, Sanvisens A, Bolao F, Tor J, Santesmases J, Pujol R, et al. Significant reductions of HIV prevalence but not of hepatitis $C$ virus infections in injection drug users from metropolitan Barcelona: 1987-2001. Drug Alcohol Depend. 2006;82:S29-33.

17. Sanvisens A, Bolao F, Vallecillo G, Torrens M, Fuster D, Pérez-Hoyos S, et al. HIV Infection and Viral Hepatitis in Drug Abusers, Current Perspectives in HIV Infection. INTECH. 2013. http://dx.doi.org/10.5772/53074. Accessed 12 November 2015.

18. Strathdee SA, Galai N, Safaiean M, Celentano DD, Vlahov D, Johnson L, et al. Sex differences in risk factors for HIV seroconversion among injection drug users: a 10-year perspective. Arch Intern Med. 2001;161:1281-8.

19. Folch C, Casabona J, Espelt A, Majó X, Meroño M, Gonzalez V, et al. Gender differences in HIV risk behaviours among intravenous drug users in Catalonia, Spain. Gac Sanit. 2013;27:338-43.

20. Magnus M, Kuo I, Phillips II G, Rawls A, Peterson J, Montanez L, et al. Differing HIV risks and prevention needs among men and women injection drug users (IDU) in the District of Columbia. J Urban Health. 2013;90:157-66.

21. Barrio G, De La Fuente L, Toro C, Brugal TM, Soriano V, Gonzalez F, et al. Prevalence of HIV infection among young adult injecting and non-injecting heroin users in Spain in the era of harm reduction programmes: gender differences and other related factors. Epidemiol Infect. 2007;135:592-603.

22. Bravo MJ, Vallejo F, Barrio G, Brugal MT, Molist G, Pulido J, et al. HCV seroconversion among never-injecting heroin users at baseline: No predictors identified other than starting injection. Int J Drug Policy. 2012;23:415-9.

23. Hacker MA, Leite I, Friedman SR, Carrijo RG, Bastos Fl. Poverty, bridging between injecting drug users and the general population, and "interiorization" may explain the spread of HIV in southern Brazil. Health Place. 2009;15:514-9.

24. Panda S, Chatterjee A, Bhattacharya S, Manna B, Singh P, Sarkar S, et al. Transmission of HIV from injecting drug users to their wives in India. Int J STD AIDS. 2000;11:468-73.

25. Strike C, Rotondi M, Kolla G, Roy É, Rotondi NK, Rudzinski K, et al. Interrupting the social processes linked with initiation of injection drug use: results from a pilot study. Drug Alcohol Depend. 2014;137:48-54.

26. Rhodes T, Bivol S, Scutelniciuc O, Hunt N, Bernays S, Busza J. Narrating the social relations of initiating injecting drug use: transitions in self and society. Int J Drug Policy. 2011;6:445-54.

27. Bravo MJ, Barrio G, De La Fuente L, Royuela L, Domingo L, Silva T. Reasons for selecting an initial route of heroin administration and for subsequent transitions during a severe HIV epidemic. Addiction. 2003;98:749-60.

28. Van Asten L, Verhaest L, Lamzira S, Hernandez-Aguado I, Zangerle R, Boufassa F, et al. Spread of hepatitis C virus among European injection drug users infected with HIV: a phylogenetic analysis. J Infect Dis. 2004;189:292-302.

29. Maisto SA, McKay JR, Connors GJ. Self-report issues in substance abuse: state of the art and future directions. Behav Assess. 1990;12:117-34. 